\title{
Atividade de Baccharis trimera (Less.) DC., (Asteraceae) sobre cultura de células in vitro
}

\author{
Yolanda Ramos Losqui, ${ }^{1}$ Felício S.S. Rozete, ${ }^{1}$ Maycon B. Almeida, ${ }^{1}$ \\ Alexandre H. C. Bittencourt, ${ }^{1}$ Simão Pedro F. Pereira ${ }^{* 1,2}$
}

\author{
${ }^{1}$ Faculdade de Minas, Av. Cristiano Ferreira Varella, 655 Bairro Universitário, Caixa Postal 36880-000 \\ Muriaé-MG, Brazil \\ ${ }^{2}$ Hospital do Câncer Muriaé, Fundação Cristiano Varella, Av. Cristiano Ferreira Varella, 655 Bairro Universitário, \\ Caixa Postal 36880-000 Muriaé-MG, Brazil
}

\begin{abstract}
RESUMO: O uso indiscriminado de plantas medicinais vem da crença de que produtos naturais não causam mal à saúde, porém assim como medicamentos sintéticos, as plantas possuem grupos de compostos farmacologicamente ativos que atuam nos organismos vivos, sendo necessário o conhecimento destes para avaliação de suas potencialidades terapêuticas e tóxicas. Estudos sobre propriedades químicas de plantas medicinais, associando o extrato destas às atividades toxicofarmacológicas, são pouco encontrados. O presente ensaio objetivou analisar a ação do óleo essencial de $B$. trimera (Less.) DC., espécie pertencente à família Asteraceae e popularmente conhecida como carqueja, sobre cultura de células do sistema nervoso central. Foram usadas células de retina de ratos neonatos tratadas pelo óleo de carqueja nas concentrações 1:500 e 1:1000, por um período de incubação de 4, 24 e 48 horas. Nossos resultados demonstram que a carqueja possui ação inibitória na diferenciação de células neuronais in vitro quando tratadas cronicamente. Observamos também uma redução na sobrevida de células neuronais e diminuição da proliferação de células gliais. Essa redução da proliferação de células da glia poderia estar interferindo na sobrevivência e diferenciação neuronal. Maiores estudos são necessários para se compreender os mecanismos envolvidos nesse efeito.
\end{abstract}

Unitermos: Carqueja, óleo essencial, cultura de células, Baccharis trimera.

\begin{abstract}
Activity of Baccharis trimera (Less.) DC. Asteraceae on culture of retinal ganglion cells in vitro". The indiscriminate use of medicinal plants comes from the belief that natural products don't cause harm to health, but as well as synthetic drugs, plants have groups of pharmacologically active compounds that act in living organisms, with the necessary knowledge of these groups to evaluate the therapeutic and toxic potential. Studies of chemical properties of medicinal plants, involving the toxicfarmacologics activities of these extracts are hardly found. This study aimed to analyze the action of essential oil of $B$. trimera (Less.) DC., a species belonging to the Asteraceae family and popularly known as carqueja, on cultured cells of central nervous system. We used retinal cells from newborn rats treated by carqueja's oil, with concentrations 1:1000 and 1:500, for an incubation period of 4, 24 and 48 hours. Our results showed that carqueja has inhibitory action on the differentiation of neuronal cells in vitro when treated chronically. We also observed a reduction in survival of neuronal cells and decreased proliferation of glial cells. This reduction of the proliferation of glial cells could be interfering with the survival and neuronal differentiation. Further studies are needed to understand the mechanisms involved in this effect.
\end{abstract}

Keywords: Carqueja, essencial oil, cell culture, Baccharis trimera.

\section{INTRODUÇÃO}

Plantas medicinais, assim como os medicamentos sintéticos, possuem grupos de compostos farmacologicamente ativos que atuam nos organismos vivos. O emprego terapêutico dessas plantas exige o conhecimento prévio de seus compostos para a avaliação

*E-mail:simaopedro@faminas.edu.br das potencialidades terapêuticas. Sua toxicidade também é de grande importância, para conseguir uma formulação apropriada e uma estratégia adequada para seu uso. As plantas, utilizadas popularmente devido a sua atividade medicinal, podem conter substâncias que oferecem ação tóxica, mutagênica e até carcinogênica quando utilizadas de maneira indiscriminada. Equivocadamente a cultura popular acredita que fazer uso exagerado de determinada 
planta não causa mal algum, pelo simples fato desta ser de origem natural. Estudos de toxicidade com plantas medicinais são pouco realizados, principalmente, avaliando sua ação em nível celular (Peron et al., 2008).

Baccharis trimera (Less.) DC., Asteraceae, conhecida como carqueja é amplamente utilizada na medicina popular, seu uso é um hábito herdado dos indígenas e há séculos é utilizada para o tratamento de várias doenças. É de 1931 o primeiro registro escrito do uso da carqueja no Brasil, empregada na forma de infusão de folhas e ramos para o tratamento da esterilidade feminina e da impotência masculina, atribuindo-lhe ainda propriedades tônicas, febrífugas e estomáquicas. A partir daí, o uso medicinal aumentou, principalmente para a solução de problemas hepáticos, disfunções estomacais e intestinais, para diabetes, obesidade e reumatismo (Auler, 2004; Carreira, 2007). A carqueja é usada também como anti-helmíntico, contra anorexia, gripe, resfriado, assim como em feridas e ulcerações, entre outros (Dresch et al., 2006). Considerando o potencial terapêutico descrito para a infusão da carqueja e a falta de estudos que avaliem sua ação tóxica, foi desenvolvido um trabalho que teve como objetivo a investigação, por meio de análise citogenética, dos efeitos tóxicos em nível celular desta planta. Após os tratamentos com as duas concentrações da infusão de $B$. trimera, foi verificado que através dos testes utilizados não houve ação citotóxica, após $24 \mathrm{~h}$ de tratamento, nas células de medula óssea de ratos Wistar tratados via gavagem, indicando, assim, uma segurança maior de uso desta planta pelo homem (Peron et al., 2008).

Segundo Verdi et al. (2005), B. trimera possui atividade antimutagênica e hepatoprotetora. A literatura corrente descreve a realização de estudos sobre o uso da carqueja, tendo sido observado a redução do ciclo mitótico, em concentrações elevadas, bem como o surgimento de anormalidades cromossômicas; a planta possui baixa toxicidade por via oral, porém possui moderada toxicidade por via intraperitoneal; a administração do extrato de carqueja em ratas exerce ação abortiva, sendo contra indicada durante a gestação e a lactação (Peron et al., 2008).

Alguns modelos de culturas de células são utilizados para avaliação da atividade de determinadas substâncias químicas. Células da retina cultivadas in vitro são um excelente modelo experimental para SNC, devido a sua fácil acessibilidade e obtenção de material sem risco de contaminação com outros tecidos. Além disso, possibilita estudos farmacológicos, principalmente por possuírem variados tipos celulares comparável a outros tecidos neuronais (Cadilhe, 2006). A retina de ratos neonatos apresenta apenas seis classes de tipos neuronais e, em geral, apenas um tipo de célula glial: a célula de Müller (Ferraz, 2007). Foi na década de setenta que a primeira cultura de células de retina de mamífero foi obtida, tendo assim iniciado os estudos acerca da sobrevida das células ganglionares in vitro (Souza, 2006). Assim como outras áreas do sistema nervoso central, a retina (que é organizada como uma rede neuronal laminar) utiliza uma grande variedade de substâncias neuroativas, sendo demonstrado por análises bioquímicas que essencialmente grande maioria dos neurotransmissores encontrados no cérebro se fazem também presentes na retina (Ferraz, 2007).

A proliferação, a migração e a diferenciação de células nervosas e gliais, são etapas relacionadas ao desenvolvimento do sistema nervoso. $\mathrm{O}$ controle do número de células neuronais e gliais no sistema nervoso central (SNC) e sistema nervoso periférico (SNP), parece ser também controlado pela morte celular natural, que é um evento fisiológico bastante conservado filogeneticamente. Vários trabalhos apontam um papel importante da apoptose (morte celular programada)nas doenças neurodegenerativas e em processo de envelhecimento. Em se tratando de morfologia, a apoptose tem como características a perda de volume celular, a condensação da cromatina, a fragmentação organizada do DNA em oligonucleossomas provocada pela ativação das endonucleases, a manutenção da estrutura de outras organelas e da membrana plasmática até o seu rompimento e por fim a fagocitose dos corpúsculos apoptóticos por macrófagos e por células vizinhas; sendo a ausência de resposta inflamatória no tecido uma característica muito importante da apoptose (Cunha, 2006). O processo de morte celular pode ser induzido em diferentes tipos celulares em resposta a uma grande variedade de estímulos incluindo danos do DNA, níveis elevados de cálcio no citoplasma, entre outros. Este dado permite dizer que a morte celular natural e a apoptose são fenômenos também mediados por vias bioquímicas intracelulares que mantém certa similaridade (Pereira \& Araújo, 1997). Após um dano citotóxico ocorre a parada do ciclo celular em G1 (uma das fazes do ciclo de replicação celular). Sendo este mecanismo importante para que possa haver o reparo do DNA antes que ocorra a divisão. Quando a extensão do dano ao DNA é grande, ocorre a indução do processo de apoptose (Medina, 2008). Novos fatores envolvidos com o início do fenômeno apoptótico são a cada dia descritos, à medida que os estudos avançam. Sabe-se que a manutenção da sobrevida é mediada por fatores do ambiente extracelular que geram mudanças gênicas que constitutivamente ativam mecanismos intracelulares de manutenção da sobrevida (Eastman, 1995). O presente trabalho objetivou determinar a ação do óleo essencial de Baccharis trimera sobre células, do sistema nervoso central, em cultura de células in vitro.

\section{MATERIAIS E MÉTODOS}

\section{Material vegetal}

As amostras de Baccharis trimera (Less.) DC., Asteraceae, foram coletadas na zona rural do município de Eugenópolis-MG, Brasil, situado em latitude de $21^{\circ}$ $05^{\prime} 56^{\prime \prime}$ Sul e longitude de $42^{\circ} 11^{\prime} 13^{\prime \prime}$ Oeste, com clima 
tropical, estando o local da coleta à aproximadamente 800 $\mathrm{m}$ de altitude.

\section{Extração do óleo essencial}

A extração de óleo essencial foi feita com a planta fresca, por arraste à vapor (hidrodestilação), utilizando um extrator do tipo Clevenger. Para a avaliação da ação do óleo essencial de $B$. trimera sobre cultura de células ganglionares utilizou-se diferentes diluições $(1: 1000,1: 500)$. As diluições continham o óleo, o solvente propilenoglicol e o veículo (mesmo meio de cultura utilizado para a cultura de células): Meio 199 (GIBCO). Tendo sido previamente estabelecido o uso de propilenoglicol para dez vezes o volume do óleo a ser diluído e o volume do meio 199 em quantidade suficiente para $1 \mathrm{~mL}$ de solução para cada placa. Uma observação importante a ser feita é que cada placa continha um volume final (incluindo o meio, os diluentes, as células, o óleo etc) de $4 \mathrm{~mL}$.

As culturas de células ganglionares da retina de ratos Lister Hooded (sobre as quais foram colocadas as diluições do óleo essencial de $B$. trimera) foram feitas de acordo com o protocolo experimental descrito por Pereira \& Araújo (2001). As células foram semeadas numa concentração de $6,5 \times 10^{5}$ células $/ \mathrm{mL}$ diluídas em meio 199, sobre lamínulas pré-tratadas com poli-L-ornitina, estas foram dispostas no fundo de uma placa de Petri de $35 \mathrm{~mm}$. Deixou-se transcorrer $4 \mathrm{~h}$, acrescentou-se $1 \mathrm{~mL}$ de meio de cultura nas placas controle, e $1 \mathrm{~mL}$ da solução contendo óleo essencial nas placas "testes", tendo ambas sido mantidas 24 e 48 h, e fixadas após este tempo para que fossem posteriormente analisadas. É importante lembrar que todas as placas de amostras e controles foram feitas em triplicata.

\section{RESULTADOS E DISCUSSÃO}

A análise foi elaborada através de microfotografia em campo claro, com o aumento de 400x, as quais foram feitas utilizando-se uma Câmera fotográfica SONY, modelo DSC-S650 com comprimento focal $13 \mathrm{~mm}$. Para a avaliação dos resultados comparou-se as placas que continham o óleo essencial nas suas diluições com as placas controles (4, 24 e $48 \mathrm{~h}$ in vitro). As culturas controle $4 \mathrm{~h}$, foram fixadas, tratadas apenas com meio de cultura (199, GIBCO), acrescido de 5\% de soro fetal bovino, glutamina $2 \mathrm{mM}$, penicilina $100 \mathrm{U} / \mathrm{mL}$ e estreptomicina $100 \mu \mathrm{g} / \mathrm{mL}$, na ausência do óleo essencial. Observam-se (Figura 1a) células neuronais ou gliais diferenciadas formando grumos, onde os neurônios se sobrepõem às células gliais. $\mathrm{Na}$ Figura $1 b$ observa-se a presença de neurônio em processo de diferenciação com aparecimento dos primeiros ramos dendrítico/axonais.

As culturas controle $24 \mathrm{~h}$ foram cultivadas in vitro na presença de meio 199 suplementado e na ausência do óleo experimental. Observa-se sua exuberância iniciando a formação de monocamada de células gliais, as quais atingem a confluência em aproximadamente quinze dias após plaqueamento. Nota-se as células da glia sendo recobertas por neurônios já bem desenvolvidos formando as primeiras conexões neurais. Pode-se notar o crescimento de arborização e comunicação entre células através de rede de dendritos e axônios (Figura 2a). Na Figura 2b observa-se os primeiros debris de células mortas e presença de células já diferenciadas, como a glia indicada pela seta. Também pode-se perceber a conexão de células gliais e neuronais. Essas conexões são essenciais para a manutenção da sobrevivência das células cultivadas.

As culturas experimentais foram fixadas após $24 \mathrm{~h}$ in vitro na presença de meio 199 suplementado e adicionado óleo de Baccharis trimera (Less.) DC., Asteraceae na concentração de 1:1000 (Figuras 3a e 3b). Nas culturas tratadas com essa diluição pode-se observar a presença de células menos diferenciadas com menor quantidade de contatos entre células como se ocorresse uma inibição no crescimento da rede dendrítica e axonal. Notase claramente que o corpo celular não apresenta núcleo apoptótico indicando assim uma redução e desaceleração no processo de diferenciação. Isso pode ser notado pela redução no crescimento de processos de arborização e rede dendrítica também observado (Figuras 3a e b). A sobrevida celular foi analisada através da manutenção das culturas por $48 \mathrm{~h}$ in vitro sem troca de meio, que faz-se necessária para manutenção da sobrevivência celular por maior tempo. As células foram então fixadas após $48 \mathrm{~h}$ in vitro na presença de meio 199 suplementado e na ausência do óleo experimental. Observa-se o início de degeneração neuronal devido à pobreza de nutrientes encontrados no meio de cultura. Nota-se que a cultura já não apresenta exuberância com muitas células morrendo possivelmente por apoptose, as quais apresentam as características morfológicas descritas por Cunha (2006). As células restantes demonstram morfologia característica de células gliais que normalmente são mais resistentes (Figuras 4a e b).

As culturas experimentais foram fixadas após $48 \mathrm{~h}$ em in vitro na presença de meio suplementado 199 e adicionado óleo de $B$. trimera em duas diferentes diluições. Observa-se nas figuras $5 \mathrm{a}$ e 5 b as células sem prolongamento quando tratadas com diluição de 1:500, assim como nas Figuras 6 (a e b), nas quais as culturas foram tratadas com a diluição de 1:1000. Nota-se que a cultura com a diluição de 1:500 apresenta maior concentração celular, enquanto que na diluição de 1:1000, a presença de células está bem reduzida. O processo de toxicidade mais evidente foi observado na diluição de 1:1000 pois a cultura aparenta um estágio degenerativo mais avançado. Estes resultados apontam um outro possível efeito não tóxico e sim um efeito trófico inibido pela ação do óleo de carqueja. Pode-se notar que a cultura com menor concentração da carqueja entre as culturas apresentou uma aparência mais devastadora com menor volume celular e quase 
nenhum processo axodendrítico visível. O uso da carqueja popularmente está relacionado à ação hepatoprotetora, antireumática, antihemíntica, uso em feridas e úlceras. Recentes estudos sobre propriedades químicas de plantas medicinais, associando o extrato da carqueja demonstram que as atividades toxicofarmacológicas, são pouco encontradas em células de medula óssea de ratos Wistar (Peron et al., 2008). Entre os poucos estudos, encontrase o de Luize et al. (2005), o qual sugere que apesar da ação hemolítica encontrada para extrato de $B$. trimera, a eficácia biológica nas concentrações testadas não revelam citotoxicidade in vitro. Porém outros dados da literatura demonstram que os ensaios utilizando a carqueja apontam para uma ação abortiva em ratas Wistar e uma redução do ciclo mitótico celular além do surgimento de anormalidades cromossômicas (Verdi et al., 2005). Apesar de ser amplo o uso de culturas de células utilizando retina, o que possibilita grande quantidade de informações sobre este tecido, e permite comparar e correlacionar os resultados experimentais novos com os dados presentes na literatura (Medina, 2008). Os resultados obtidos apontam para uma redução no processo proliferativo celular com visível redução na proliferação glial de culturas tratadas com extrato de carqueja. As interações neurônio/glia tem sido responsáveis por diversos processos ligados a construção da arquitetura neuronal (Gomes et al., 2001).
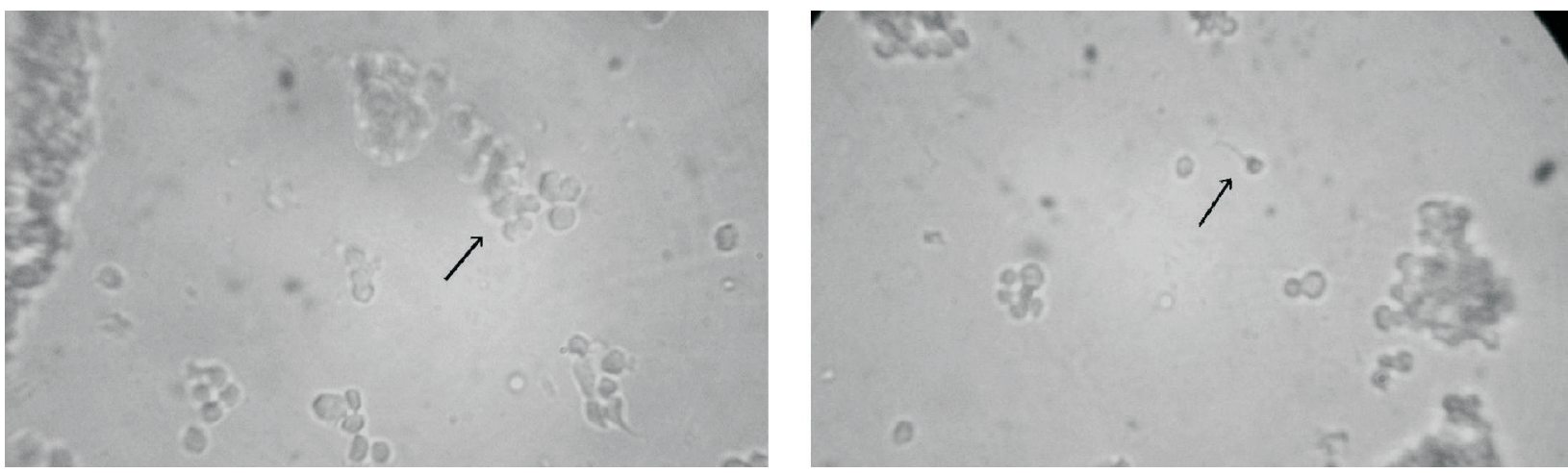

Figura 1. Cultura controle $(4 \mathrm{~h})$ sem a presença de óleo essencial; (a) formação de grumos por células neuronais ou gliais indiferenciadas, com sobreposição dos neurônios sobre as células gliais; (b) presença de neurônio diferenciando-se com aparecimento dos primeiros ramos dendrítico/axonais.
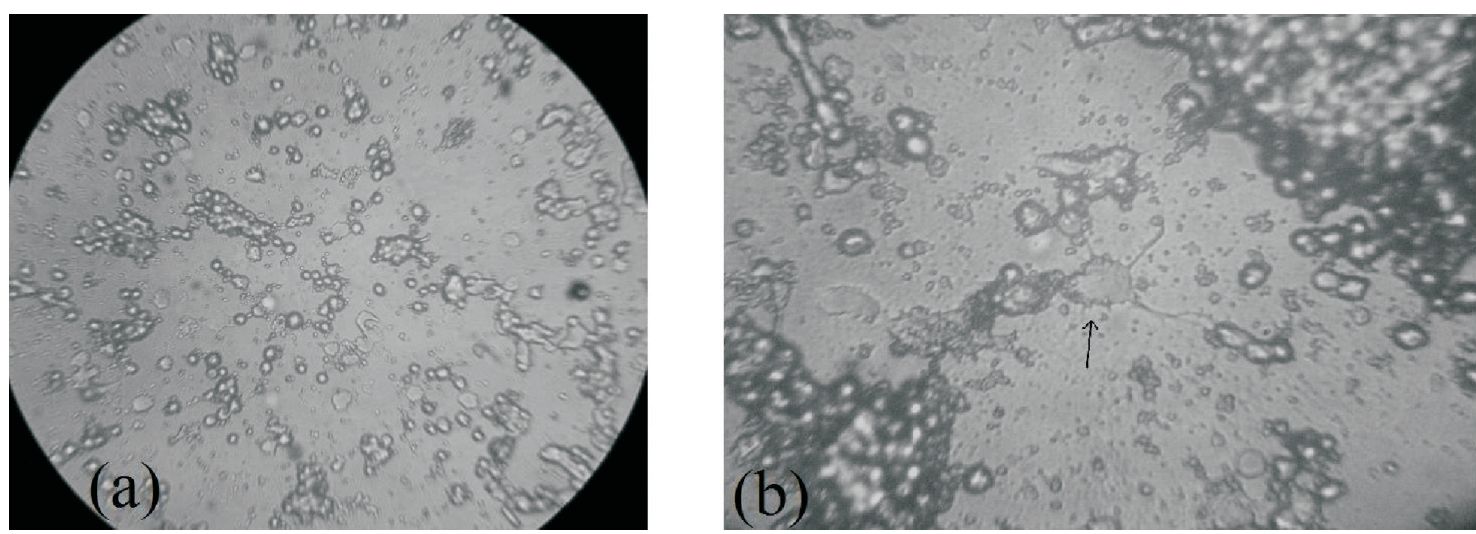

Figura 2. Cultura controle (24 h); (a) início da formação da monocamada de células neuronais; crescimento de arborização e comunicação entre células através de rede de dendritos e axônios; (b) presença de debris de células mortas e de células já diferenciadas, como a glia indicada pela seta. 

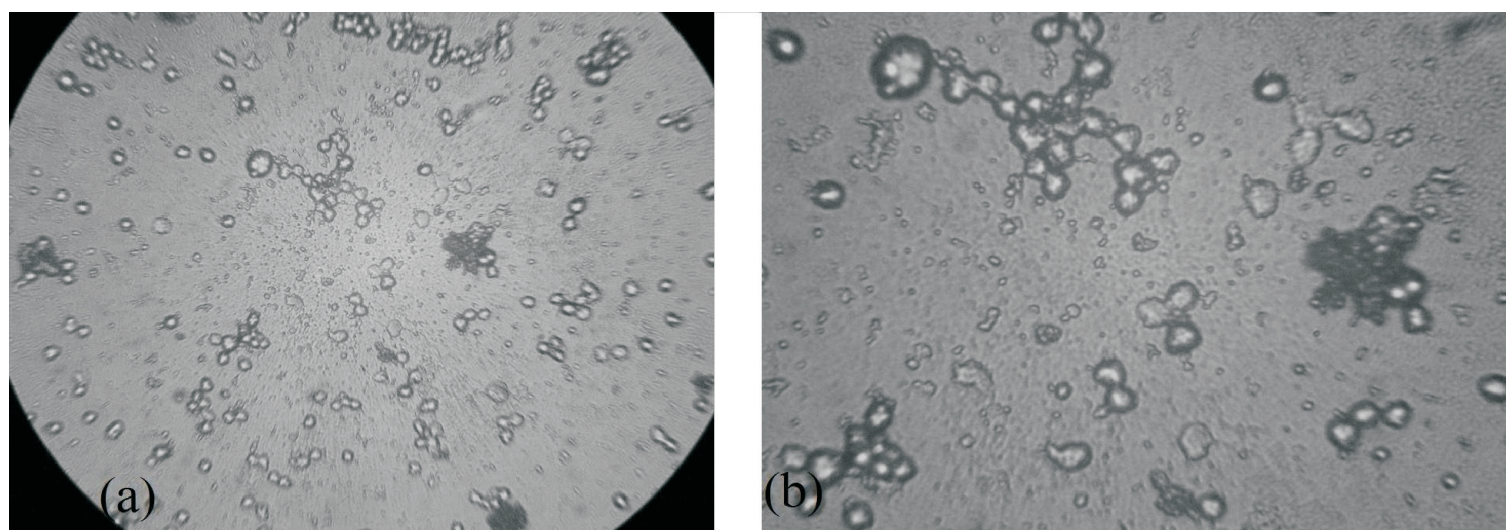

Figura 3. Cultura de 24 h com presença do óleo essencial de $B$. trimera na diluição 1:1000; (a) e (b) presença de células menos diferenciadas e com menor quantidade de contatos intercelular; possível ocorrência de inibição da rede dendrítica e axonial.
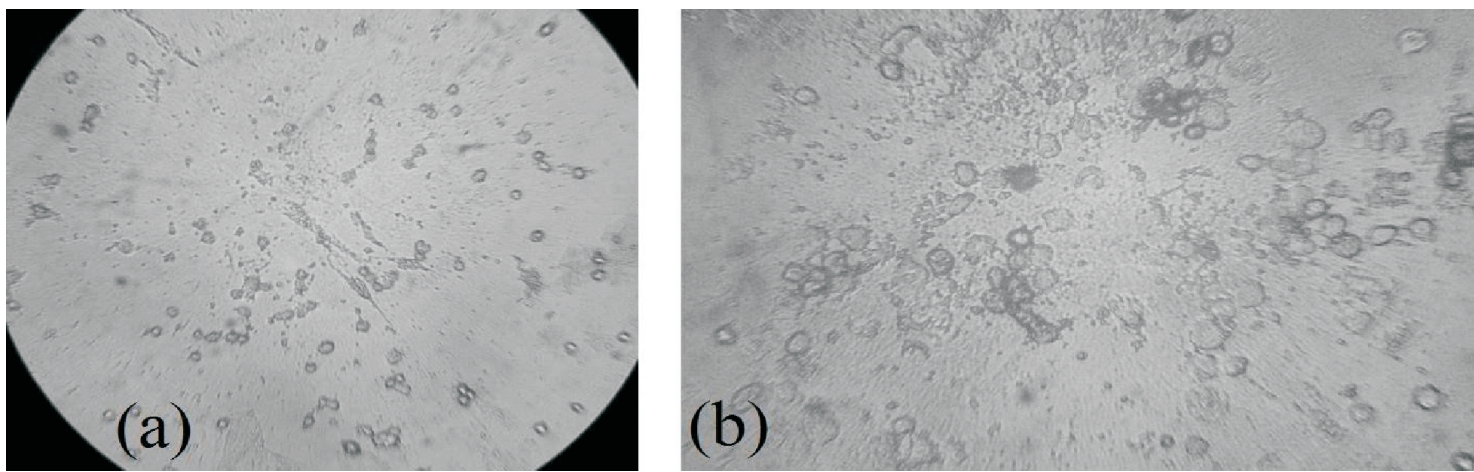

Figura 4. Cultura controle (48 h); (a) início de degeneração neuronal; a cultura já não apresenta exuberância com muitas células morrendo possivelmente por apoptose; (b) as células restantes demonstram morfologia característica de células gliais que normalmente são mais resistentes.
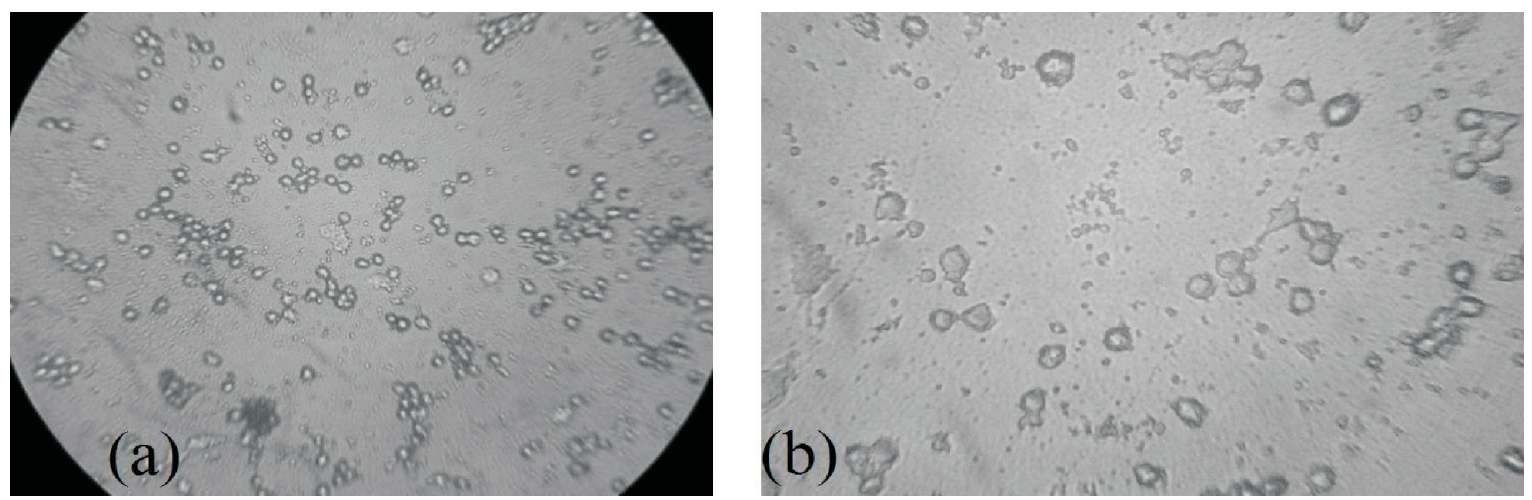

Figura 5. Cultura (48 h) com presença do óleo essencial de $B$. trimera em diluição 1:500; células sem prolongamento.
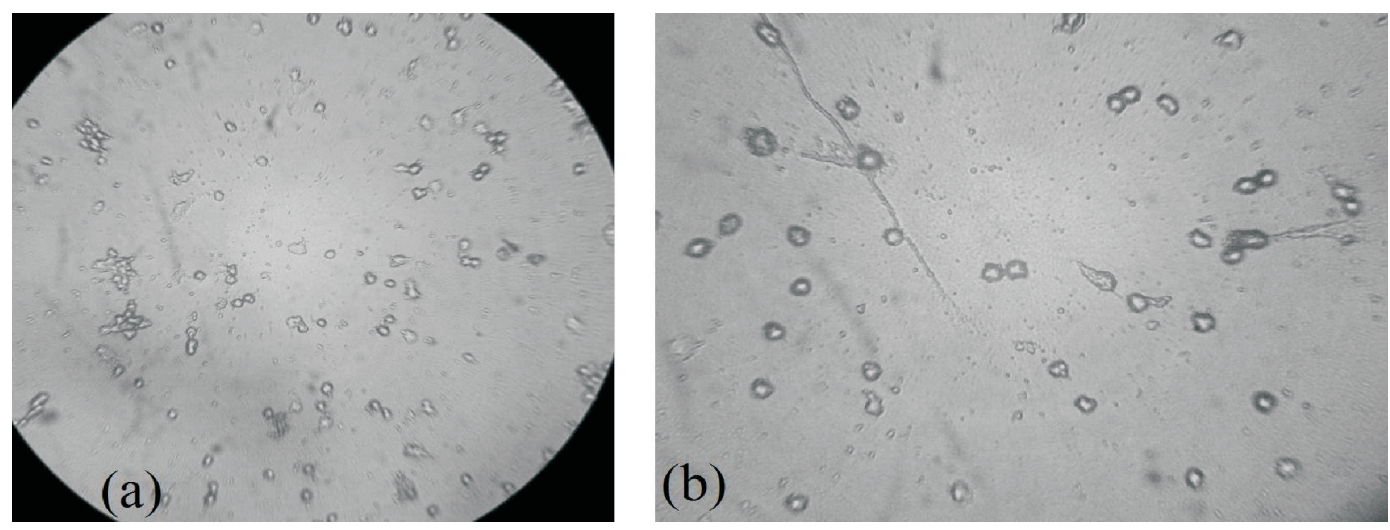

Figura 6. Cultura (48 h) com presença do óleo essencial de B. trimera em diluição 1:1000; células sem prolongamento. 


\section{AGRADECIMENTOS}

Agradecemos à FAMINAS pelo apoio e incentivo à pesquisa e a Profa. Elizabeth Giestal Araújo (Laboratório Hertha Mayer - UFF) pela colaboração e fomento para realização deste trabalho.

\section{REFERÊNCIAS}

Auler NMF 2004. Distribuição da variabilidade genética em populações naturais de Baccharis trimera (Less) DC. (carqueja) no Sul do Brasil. Santa Maria, 198p. Tese de Doutorado, Programa de Pós-graduação em Agronomia, Universidade Federal de Santa Maria.

Cadilhe DV 2006. Regulação da síntese protéica por receptores NMDA em culturas de retina: envolvimento da eEF2 cinase. Niterói, 109p. Dissertação de Mestrado, Programa de Neuroimunologia, Universidade Federal Fluminense.

Carreira RC 2007. Baccharis trimera (Less.) DC. (Asteraceae): estudo comparativo dos óleos voláteis, atividade biológica e crescimento de estacas de populações ocorrentes em áreas de Cerrado e Mata Atlântica. São Paulo, 191p. Tese de Doutorado, Instituto de Botânica da Secretaria do Meio Ambiente.

Cunha KCS 2006. Sobrevida das células ganglionares da retina induzida pelo PMA: envolvimento da PKC/ e JNK. Niterói, 63p. Dissertação de Mestrado, Programa de Neuroimunologia, Universidade Federal Fluminense.

Dresch AP, Montanha JA, Matzenbacher NI, Mentz LA 2006. Controle de qualidade de espécies do gênero Baccharis L. (Asteraceae) por CCD a partir de extratos rápidos. Infarma 18: 37-40.

EastmanA1995. Survival factors, intracellular signal transduction, and the activation of endonucleases in apoptosis. Semin Cancer Biol 6: 45-52.

Ferraz CVVG 2007. FGFb aumenta a proliferação de células da retina em cultura: vias de sinalização envolvidas. Niterói, 160p. Tese de Doutorado, Programa de Neuroimunologia, Universidade Federal Fluminense.

Garcia-Abreu J, Moura neto V, Carvalho SL, Cavalcante LA 1995. Regionally specific properties of midbrain glia: interactions with midbrain neurons. $J$ Neurosci Res 40: 417-477.

Gomes FCA, Spohr TCLS, Martinez R, Moura Neto V 2001. Cross-talk between neurons and glia: highlights on soluble factors. Braz J Med Biol Res 34: 611-620.

Lim DA, Alvarez-Buylla A 1995. Interaction between astrocytes and adult subventricular zone precursors stimulates neurogenesis. P Natl Acad Sci Usa 96: 7526-7531.

Luize PS, Tiuman TS, Morello LG 2005. Effects of medicinal plant extracts on growth of Leishmania (L.) amazonensis and Trypanosoma cruzi. Rev Bras Cien Farm 41: 85-94.

Medina SV 2008. IGF-I aumenta a proliferação de células da retina: vias de sinalização envolvidas. Niterói, 103p Tese de Doutorado, Programa de Neuroimunologia, Universidade Federal Fluminense.
Pereira SPF, Araújo EG 1997. Veratridine increase the survival of retinal ganglion cells in vitro. Braz J Med Biol Res 30: 1467-1470.

Pereira SPF, Araújo EG 2001. Cholinergic activity modulates the survival of retinal ganglion cells in culture: The role of M1 muscarinic receptors. Int J Dev Neuroci 19: 559567.

Peron AP, Felipes J, Mattge GI, Cantagalli LB, Mariucci RG, Vicentini VEP 2008. Avaliação mutagênica das plantas medicinais Baccharis trimera Less. e Solanum melongena L. em células de medula óssea de ratos Wistar. Rev Bras Biocien 6: 127-130.

Pfrieger FW, Barres BA 1997. Synaptic Efficacy Enhanced by Glial Cells in Vitro. Science 277: 1684-1687.

Souza LOJ 2006. IL-2 e a sobrevida de neurônios centrais. Niterói, 48p Dissertação de Mestrado, Programa de Neuroimunologia, Universidade Federal Fluminense.

Verdi LG, Brighente IMC, Pizzolatti MG 2005. Gênero Baccharis (Asteraceae): aspectos químicos, econômicos e biológicos. Quim Nova 28: 85-94. 